\title{
An Evaluation of a Secure Email Service (Healthmail): A Cross-sectional Survey of Irish GPs
}

\author{
James Larkin ${ }^{1}$, Ivana Pericin' ${ }^{1}$, Brian O’Mahoney ${ }^{2}$, Karina Hull ${ }^{3}$, Claire Collins, ${ }^{1, *}$ \\ ${ }^{1}$ Research Department Irish College, Dublin, Ireland \\ ${ }^{2}$ General Practice Information Technology (GPIT) Group, Irish College of General Practitioners, Dublin, Ireland \\ ${ }^{3}$ Healthlink, Kings Inn House, Ireland
}

Copyright $(2018$ by authors, all rights reserved. Authors agree that this article remains permanently open access under the terms of the Creative Commons Attribution License 4.0 International License

\begin{abstract}
Securing sensitive patient information has become increasingly important after cyber-attacks on healthcare systems. Many current forms of communication such as fax and letter are insecure. Effective cybersecurity can increase patient safety. Healthmail is a secure email service which acts as a means of transferring patient information. Healthmail is available to a range of Irish medical workers. An online survey was sent to Healthmail account holders and to general practitioners (GPs) in Ireland. Self-declared GP account holders' responses were examined to evaluate their usage of Healthmail, opinions on Healthmail's merits and suggestions for improving Healthmail. The response rate was $19.5 \%$ (276/1415). Over half $(51.5 \%)$ of respondents sent at least one Healthmail email in the previous week. Overall, 64.7\% $(n=178)$ of respondents said Healthmail improves patient care. Also, $58.7 \%(n=155)$ of respondents said Healthmail should be expanded to other disciplines. Many respondents (40.5\%) said they would be happy to communicate with patients using secure email. These results suggest that Healthmail's perceived utility is high and could increase. Therefore, Healthmail has the potential to become part of mainstream communication between healthcare workers.
\end{abstract}

Keywords Healthmail, Electronic Mail, Primary Care, General Practice

\section{Introduction}

Healthmail [1] is a secure clinical email service with access controls. It was introduced in 2014 and the number of registered accounts has steadily increased to 2,367 as of December 2017, with a large increase since May 2018 [2]. Healthcare workers need an effective means of communication to care for patients adequately [3]. The Irish health service currently uses several methods of communication between healthcare workers including structured messages via Healthlink and fax, phone and letter. Letters and fax can easily be intercepted. Phone calls, though more secure, do not facilitate record keeping. However, large scale interception of data is less feasible with these forms of communication when compared to email [4].

"Effective cybersecurity is fundamental to patient safety." [5]. The recent Wannacry ransomware attack on the National Health Service in Britain [6] has highlighted the vulnerability of sensitive patient information in the information technology age. There have been several examples of cyber-attacks on healthcare organisations [7]. According to the 1995 European Union Directive on Data Protection, it is the responsibility of health data controllers to provide their patients with assurances that their data is secure [8]. Also, the new General Data Protection Regulation (GDPR) makes 'data protection by design' a legal obligation [9]. One way patient data can be protected is through secure clinical email with access controls.

Healthmail facilitates healthcare providers in transferring sensitive patient information securely. All agencies connected to Healthmail have transport layer security (TLS) which encrypts data in transit, preventing interception of sensitive data. The hard drives of the Healthmail servers are encrypted using Microsoft Bitlocker. Healthmail operates using a private bounded network and has access controls only allowing authenticated third parties to send and receive Healthmail emails. Also, Healthmail provides read receipts. A Cochrane review [10] of email communication describes encryption, access controls and read receipts as necessary elements of secure email services. Healthmail is available to all GPs and community pharmacies $^{\mathrm{a}}$ in Ireland, once they register for an account. Clinicians in the Irish Health Services

a This study was carried out before Healthmail was made available to pharmacies 
Executive (HSE) and Voluntary Hospitals are automatically securely connected to Healthmail from their institutional accounts. Similar systems to Healthmail exist internationally such as NHS Mail in Great Britain. The researchers are not aware of any evaluations of services of this kind. A Cochrane review [10] concludes that there is a dearth of research on email as a means of communication between healthcare professionals.

With most patient information transferring from analogue to digital format, a concern of patients and healthcare providers [11] is privacy. In one survey $50 \%$ of patients agreed/strongly agreed that they were worried about health information being transferred over the internet [12].

There are several ways, other than security, that Healthmail can improve patient care. By functioning as a separate email solution, designated specifically for healthcare communication, it might overcome some of the difficulties with informality when standard email is used [13]. Also, as outlined by Atherton, Car and Meyer [14], the use of email between healthcare providers has advantages such as asynchronous communication, low cost and quick, and a simple means of transferring digital images. However, email can be slower than direct verbal communication. Also, the uptake of information technology such as email has been slow in health services [15].

A review of email communication between healthcare providers suggests that much of the research on this topic is conducted in North America and may not be applicable internationally due to different types of email technology and levels of availability [16].

In this context, this research sought to evaluate the usage patterns of Healthmail account holders, their opinions on Healthmail and their suggestions for improving Healthmail.

\section{Methods}

A cross-sectional design was used. An online survey was sent to all Healthmail account holders and to all members of the Irish College of General Practitioners (who may or may not be Healthmail account holders). For this paper, only those who were both GPs and self-declared that they have a Healthmail account were subject to analysis. The survey was sent to 1,541 Healthmail account holders on the 30th of January, 2017. Of these, 1,415 were GPs. Notices of the questionnaire were also placed on the Irish College of General Practitioners (ICGP), General Practices Information Technology (GPIT) and HSE websites, and in Forum, the monthly ICGP magazine. Responses were anonymous. To incentivise questionnaire completion, all participants were entered into a draw to win free registration to the ICGP's annual meeting.

The survey questions (appendix A) were developed in conjunction with an Irish GP who uses Healthmail and was involved in the development of the Healthmail service. Questions in the survey covered respondents' self-declared Healthmail usage, their experiences of Healthmail and their thoughts on improving Healthmail. The survey questions were mostly multiple choice questions. There were several qualitative questions but only one of these was subject to analysis for this paper: 'What do you mainly use Healthmail for?' The study and the survey were considered by the ICGP ethics committee. However, ethical approval was not deemed necessary given the nature of the research. The survey was piloted with ten GPs who use Healthmail. They each provided feedback, which was discussed and incorporated into a revised survey where appropriate.

Data was analysed using v25 of SPSS.

\section{Results}

Overall, 276 GP Healthmail account holders responded to the questionnaire, representing a response rate of $19.5 \%$. Respondents were asked whether their practice area was 'Urban' (population of over 5,000 people), 'Rural' or 'Mixed'. Overall, 54.2\% $(\mathrm{n}=226)$ worked in an 'Urban' area, $18.5 \%(n=51)$ in a 'Rural' area and $27.3 \%(n=75)$ in a 'Mixed' area. A breakdown of GP demographic information is in Table 1.

Table 1. GP respondents' age, gender and Community Health Organisation

\begin{tabular}{|c|c|c|}
\hline & Valid percentage & $\mathrm{n}$ \\
\hline \multicolumn{3}{|c|}{ Age } \\
\hline$<35$ & 5.1 & 14 \\
\hline $35-54$ & 63.0 & 174 \\
\hline$>54$ & 31.9 & 88 \\
\hline \multicolumn{3}{|c|}{ Gender } \\
\hline Female & 40.9 & 113 \\
\hline Male & 59.1 & 163 \\
\hline \multicolumn{3}{|c|}{$\begin{array}{l}\text { What Community Health Organisation }{ }^{\mathrm{b}}(\mathrm{CHO}) \text { respondents are } \\
\text { working in }\end{array}$} \\
\hline CHO 1 & 7 & 19 \\
\hline CHO 2 & 15.1 & 41 \\
\hline CHO 3 & 7.7 & 21 \\
\hline CHO 4 & 15.4 & 42 \\
\hline CHO 5 & 9.9 & 27 \\
\hline CHO 6 & 11.8 & 32 \\
\hline CHO 7 & 12.1 & 33 \\
\hline CHO 8 & 8.8 & 24 \\
\hline CHO 9 & 12.1 & 33 \\
\hline
\end{tabular}

b Nationally, services outside of acute hospitals are broken into nine community health organisations. These services include primary care. 
Table 2. Tests of association between use of Healthmail and demographic factors

\begin{tabular}{|c|c|c|c|c|c|c|c|c|c|}
\hline \multirow[t]{2}{*}{ Characteristic } & \multirow[t]{2}{*}{ Group } & \multirow[t]{2}{*}{ No. } & \multicolumn{4}{|c|}{ Sample percentages } & \multicolumn{3}{|c|}{ Ordinal regression } \\
\hline & & & None & $<5$ & $5-10$ & $>10$ & OR & $95 \% \mathrm{CI}$ & $p$ \\
\hline \multicolumn{10}{|c|}{ How many Healthmail emails have you sent in the previous week } \\
\hline \multirow[t]{2}{*}{ Gender } & Female & 113 & 54.1 & 25.2 & 9.9 & 10.8 & . & & \\
\hline & Male & 163 & 44.8 & 39.9 & 9.8 & 5.5 & 1.20 & $0.75-1.92$ & .45 \\
\hline \multirow[t]{2}{*}{ Age } & $>54$ & 88 & 50 & 28.4 & 11.4 & 10.2 & . & & \\
\hline & $\leq 54$ & 188 & 47.8 & 36.6 & 9.1 & 6.5 & 1.02 & $0.62-1.66$ & .95 \\
\hline \multirow[t]{3}{*}{ Area } & Urban & 141 & 55.4 & 30.4 & 7.4 & 6.8 & . & & \\
\hline & Rural & 51 & 42 & 32 & 16 & 10 & 1.86 & $1.01-3.43$ & .046 \\
\hline & Mixed & 75 & 40 & 42.7 & 9.3 & 8 & 1.64 & $0.97-2.78$ & .07 \\
\hline
\end{tabular}

Account holders were asked in what setting they use Healthmail, 99.3\% $(\mathrm{n}=274)$ responded 'GP practice', and $0.7 \%(n=2)$ said an 'Out of hours Co-op'c .

Account holders were asked how many Healthmail emails they had sent in the previous week and $48.5 \%(\mathrm{n}=$ 133) had sent no emails in the previous week, $33.9 \%(\mathrm{n}=$ 93) had sent less than five, 9.9\% $(n=27)$ had sent between five and nine, and 7.7\% $(\mathrm{n}=21)$ had sent more than 10 . Chi square tests were conducted to examine whether a relationship existed between the number of Healthmail emails sent in the previous week and demographic variables; gender, age and area. No significant relationships were found. A multiple ordinal regression was conducted to examine the relationship between respondent demographics and Healthmail usage (Table 2). In this regression, area was significantly related to Healthmail usage; those from a rural area were more likely to have sent more Healthmail emails in the previous week compared to those from an urban area.

Those with an account were asked who they are communicating with using Healthmail, $60.1 \%(\mathrm{n}=166)$ said GPs. Further detail can be seen in Figure 1.

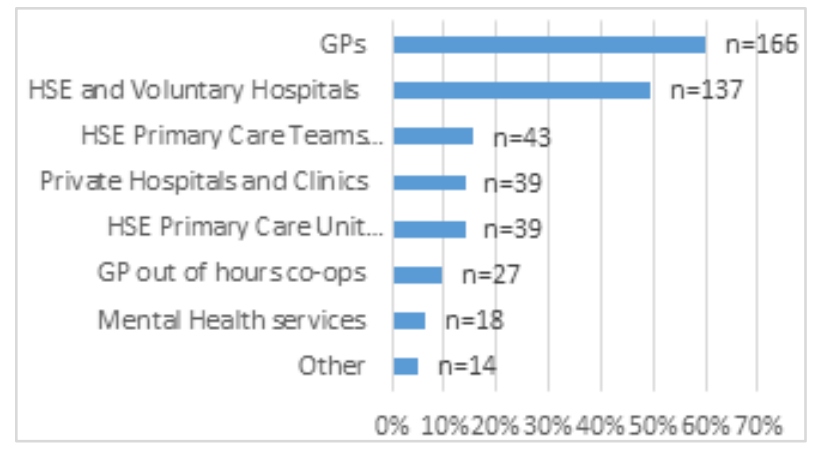

Figure 1. Who Healthmail account holders are communicating with using Healthmail

Respondents were also asked what they 'mainly use Healthmail for'. The most prominent themes are seen in

c An out of hours GP service for patients, active from $6.00 \mathrm{pm}$ to $8.00 \mathrm{am}$ on Monday to Friday, and for 24 hours on Saturdays, Sundays and state holidays.
Table 3, along with relevant examples.

Table 3. Examples of how Healthmail is being used

\begin{tabular}{|c|c|}
\hline Themes & Examples \\
\hline Bureaucratic & $\begin{array}{c}\text { 'To transfer patient notes' } \\
\text { 'Exchanging patient records' }\end{array}$ \\
\hline Queries & $\begin{array}{c}\text { 'Urgent queries with consultants' } \\
\text { 'Seeking advice to prevent referrals' }\end{array}$ \\
\hline Results & 'Blood and x ray results' \\
\hline Referrals & $\begin{array}{c}\text { 'Referral to consultants' } \\
\text { 'Referrals to primary care team' }\end{array}$ \\
\hline
\end{tabular}

Participants were also asked if they think the Healthmail service should continue and $80.8 \%(\mathrm{n}=223)$ relayed that it should, $5.4 \%(\mathrm{n}=15)$ said it should not and $13.8 \%(\mathrm{n}=38)$ said that they 'don't know'.

Overall, $64.7 \%(\mathrm{n}=178)$ of respondents said they think Healthmail improves patient care, $15.3 \%(n=42)$ said that they thought it does not and $20 \%(\mathrm{n}=55)$ said they 'don't know'.

Respondents were asked if they would be happy to communicate with patients using a 'secure email solution', $40.5 \%(n=111)$ said they would, $39.1 \%(n=107)$ said they would not and $20.4 \%(\mathrm{n}=56)$ said they 'don't know'

The questionnaire also asked whether one would like Healthmail availability to be expanded to other disciplines. Overall, $58.7 \%(\mathrm{n}=155)$ of respondents said they would, $14.8 \%(n=39)$ said they would not and $26.5 \%(n=70)$ said they 'don't know'.

Chi square tests were conducted to examine whether a relationship existed between responses to several questions about respondents' opinions of Healthmail (Table 4) and demographic variables; gender, age and area. Due to small cell counts, 'don't know' and 'no' responses were combined and compared to 'yes' responses. A significant relationship was found between gender and whether the Healthmail service should be expanded to other disciplines $\chi^{2}(1, n=$ $264)=6.44, p<.05$. A multiple logistic regression was conducted to investigate whether demographic factors significantly predicted opinions on Healthmail, the results of which are displayed in Table 4. In this, the only significant finding was that gender predicted response on whether respondents would like to see Healthmail expanded to other disciplines. 
Table 4. Tests of association between opinions of Healthmail and demographic factors

\begin{tabular}{|c|c|c|c|c|c|c|}
\hline \multirow[t]{3}{*}{ Characteristic } & \multirow[t]{3}{*}{ Group } & \multirow[t]{3}{*}{ No. } & & & & \\
\hline & & & \multicolumn{4}{|c|}{ OR $(95 \% \mathrm{CI})$} \\
\hline & & & Yes & No & Yes versus no & $p$ \\
\hline \multicolumn{7}{|c|}{ Should the Healthmail service continue } \\
\hline \multirow[t]{2}{*}{ Gender } & Female & 113 & 79.6 & 20.4 & . & \\
\hline & Male & 163 & 81.6 & 18.4 & $1.08(0.58-2.01)$ & .81 \\
\hline \multirow[t]{2}{*}{ Age } & $\leq 54$ & 188 & 80.9 & 19.1 & $\cdot$ & \\
\hline & $>54$ & 88 & 80.7 & 19.3 & $1.04(0.54-2.03)$ & .90 \\
\hline \multirow[t]{3}{*}{ Area } & Urban & 149 & 79.9 & 20.1 & . & \\
\hline & Rural & 51 & 74.5 & 25.5 & $0.73(0.34-1.57)$ & .42 \\
\hline & Mixed & 75 & 86.7 & 13.3 & $1.63(0.75-3.54)$ & .22 \\
\hline \multicolumn{7}{|c|}{ Does Healthmail improve patient care } \\
\hline \multirow[t]{2}{*}{ Gender } & Female & 113 & 61.9 & 38.1 & . & \\
\hline & Male & 162 & 66.7 & 33.3 & $1.20(0.72-2.00)$ & .49 \\
\hline \multirow[t]{2}{*}{ Age } & $\leq 54$ & 188 & 65.4 & 34.6 & . & \\
\hline & $>54$ & 87 & 63.2 & 36.8 & $0.94(0.54-1.62)$ & .82 \\
\hline \multirow[t]{3}{*}{ Area } & Urban & 149 & 62.4 & 37.6 & $\cdot$ & \\
\hline & Rural & 51 & 56.9 & 43.1 & $0.81(0.42-1.56)$ & .53 \\
\hline & Mixed & 74 & 74.3 & 25.7 & $1.72(0.92-3.19)$ & .09 \\
\hline \multicolumn{7}{|c|}{ Would you be happy communicate with patients via Healthmail } \\
\hline \multirow[t]{2}{*}{ Gender } & Female & 112 & 33.9 & 66.1 & . & \\
\hline & Male & 162 & 45.1 & 54.9 & $\begin{array}{c}1.67 \\
(1.00-2.784)\end{array}$ & .049 \\
\hline \multirow[t]{2}{*}{ Age } & $\leq 54$ & 186 & 41.4 & 58.6 & . & \\
\hline & $>54$ & 88 & 38.6 & 61.4 & $0.85(0.50-1.45)$ & 0.54 \\
\hline \multirow[t]{3}{*}{ Area } & Urban & 148 & 40.5 & 59.5 & . & \\
\hline & Rural & 51 & 37.3 & 62.7 & $0.92(0.47-1.80)$ & .81 \\
\hline & Mixed & 74 & 41.9 & 58.1 & $1.01(0.57-1.79)$ & .98 \\
\hline \multicolumn{7}{|c|}{ Would you like to see Healthmail expanded to other disciplines } \\
\hline \multirow[t]{2}{*}{ Gender } & Female & 109 & 49.5 & 50.5 & . & \\
\hline & Male & 155 & 65.2 & 34.8 & $1.90(1.14-3.17)$ & .01 \\
\hline \multirow[t]{2}{*}{ Age } & $\leq 54$ & 181 & 58.0 & 42.0 & . & \\
\hline & $>54$ & 83 & 60.2 & 39.8 & $1.03(0.59-1.78)$ & .93 \\
\hline \multirow[t]{3}{*}{ Area } & Urban & 140 & 60.7 & 39.3 & . & \\
\hline & Rural & 51 & 52.9 & 47.1 & $0.74(0.38-1.43)$ & .36 \\
\hline & Mixed & 73 & 58.9 & 41.1 & $0.86(0.48-1.55)$ & .62 \\
\hline
\end{tabular}


Participants were asked if Healthmail was expanded who they would like to see it expanded to and $50 \%(\mathrm{n}=138)$ said pharmacists. Further detail of who respondents would like to see access to Healthmail expanded to can be seen in Figure 2.

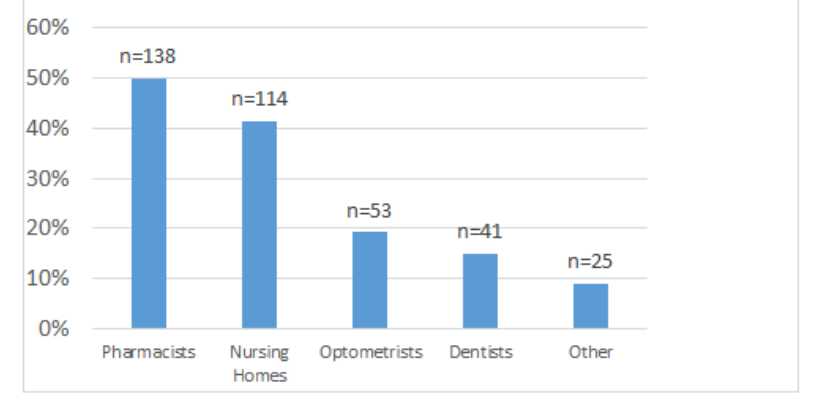

Figure 2. Who respondents would like to see Healthmail expanded to

Respondents were also provided with a list of potential suggestions to change Healthmail; $85.1 \%(n=235)$ of participants suggested integrating Healthmail with the GP practice software system. Further information can be seen in Figure 3.

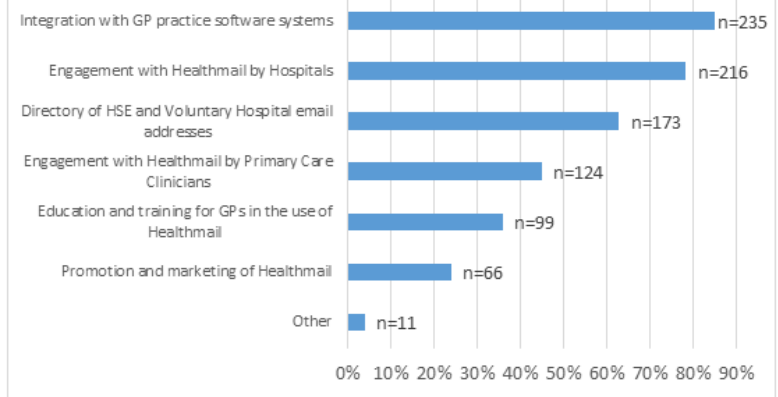

Figure 3. Respondents' suggestions for making Healthmail more useful

\section{Discussion}

Healthmail, a secure means of transferring sensitive patient data, appears to be widely used and a service that Healthmail account holders would like to see continue. Despite the high number of accounts registered, usage of Healthmail might be considered low. Going forward, there are several strategies that might entice people to register accounts and to use them more often. This may involve expanding Healthmail access to other professions and integrating Healthmail with GP practice software systems.

The study found that most Healthmail account holders who are GPs are positive about Healthmail with the majority $(64.7 \%)$ thinking that it improves patient care and an even greater number $(80.8 \%)$ wanting the service to continue.

Healthmail was being used for a variety of purposes. One of the primary uses described was the transfer of patient notes between GPs. Healthmail was also used for clinical queries to consultants and primary care staff. Several respondents relayed that they mainly use Healthmail for referrals to consultants. However, referrals to consultants are the intended use of another electronic messaging service; Healthlink [17].

The fact that $48.5 \%$ of GP account holders had sent no Healthmail emails in the previous week may indicate that despite registering for Healthmail that account holders are not using it. Nonetheless, $51.5 \%$ of GP account holders stated that they are sending at least one Healthmail email a week. It is unclear what communication method is being used instead of Healthmail for transferring sensitive patient information. Another study involving GPs [18] found that email communication was used by almost all GPs involved in the study. The technology acceptance model describes what effects uptake and use of information technology [19]. Two of the major aspects of the model are perceived usefulness and perceived ease of use. Given that the most suggested improvement for Healthmail is to integrate it with GP practice software systems, this implies that ease of use may play a role in the low usage. A study of Finnish physicians found ease of use played a major role in email usage [18]. Also, since GDPR came into effect in May 2018, usage of Healthmail has greatly increased [2]. This might imply that the perceived usefulness was low due to weak legislation around data protection.

Education and training was highlighted by only $35.9 \%$ of respondents as a means of improving Healthmail despite the fact that a review on email communication between physicians specifies that education and training are needed to ensure competent users of a technology [10]. Two other suggestions: engagement with Healthmail by hospitals, and engagement with Healthmail by primary care physicians were highly recommended with $78.3 \%$ and $44.9 \%$ of respondents respectively suggesting these. Engagement by hospitals and primary care clinicians could be heavily influenced by education and training. Education, training and ongoing support increase the effectiveness of the implementation of a technology [20]. Though this will require a concerted effort as current systems of communication such as phone, letter and fax are long embedded in the Irish system, and an awareness of the security of Healthmail may be lacking. Amongst GPs, promotion, education and training might be targeted at those from an urban area as they were significantly more likely to have sent less Healthmail emails in the previous week when compared with GPs from a rural area.

Amongst respondents, $60.1 \%$ said they communicate with GPs using Healthmail. The majority $(58.7 \%)$ of participants would like to see Healthmail expanded. The most suggested profession to expand Healthmail to was Pharmacy (50\%). This has since been implemented in April 2017 and involves discussions between GPs and pharmacists about prescriptions. After that, $41 \%$ of respondents wanted the service expanded to nursing homes. However, it is unclear as to whether it would be acceptable 
to setup Healthmail for nursing home staff.

Furthermore, $40.5 \%$ of respondents said they would be happy to communicate with patients using secure email. It is unclear what kind of contact this would involve. With doctors increasingly communicating with patients via email $[21,22]$ and patients wanting more email communication with doctors [23], this implies that secure email communication might be acceptable to some Irish healthcare staff. However, further research is needed as there are legal implications as well as potential concerns amongst GPs regarding workload and payment. In the UK, the use of email to contact patients is not obligatory, however, it is endorsed by the Department of Health [24] and the Royal College of General Practitioners [25].

Regarding limitations, it is likely that a participation bias exists whereby those who use Healthmail more often are more likely to respond to a survey about Healthmail. Also, information about the survey was only available via the internet and email, therefore those who are more technologically engaged are more likely to be aware of the survey. The study reported account holders' stated Healthmail usage and not their actual usage which may have led to a response bias. Use of this proxy measure undermines the validity of the results. The response rate of $19.5 \%$ is low which reduces the validity of the results. However, the respondents were distributed relatively evenly across Ireland's nine community health organisations, which improves the generalisability of the findings. As well, the age and gender of responding GPs were representative of the national profile of GPs in Ireland [26]. Notably, similar response rates for GPs have been seen in Ireland and abroad [27, 28]. This may be due to the heavy workload related to general practice [29]. Monetary incentives and mixed-mode surveys have been shown to improve response rates amongst physicians [27].

\section{Conclusions}

The uptake of information technology in healthcare has been slow elsewhere [15] and the results here are similar. However, in Ireland, Healthmail's perceived utility is high among users and therefore, a secure email service has the potential to become part of mainstream communication between healthcare staff and also between GPs and patients. Education and training are essential to increasing uptake. Privacy is a key concern in the sharing and transfer of patient information [11, 12, 13], but Healthmail could provide an acceptable solution.

\section{Acknowledgements}

Healthmail is a service of the Primary Care Division of the HSE. It was implemented with the support of the ICGP, the Irish Pharmacy Union, the Department of Health and eHealth Ireland. 


\section{Appendix}

\section{Healthmail Evaluation Survey}

Introduction

Healthmail, secure clinical email, has been in operation for two years. It is now time to evaluate Healthmail, to help decide whether it is a worthwhile service and should continue to be funded by the HSE. We would be grateful if you could complete this brief ( 5 minute) online questionnaire, whether you are a Healthmail user or not. If you use Healthmail, we are particularly keen to hear your stories of instances in which Healthmail assisted you and your patients. Your responses are anonymous and your help is much appreciated.

We have tried to keep this survey as simple as possible; there are some mandatory questions, denoted with an *, but we have kept these to a minimum.

Thank you for your assistance.

Brian O'Mahony, GPIT Project Manager

Karina Hull, eHealth Ireland

Claire Collins, Director of Research, ICGP

* 1 . Do you have a Healthmail account? (i.e. do you have a Healthmail email address?)
Yes, personal Healthmail email
Yes, practice/service Healthmail email
No
Don't know 
Healthmail Evaluation Survey

* 2. In which setting do you mainly use Healthmail? (tick only one)

GP Practice

HSE Agency

Voluntary Agency

Out of hours Co-op

Pharmacy

Other

Other (please specify) 
Healthmail Evaluation Survey

* 3 . What is your role in the practice?

GP

Practice Nurse

Practice Manager

Secretary/Receptionist

Other

Other (please specify)

* 4. How often do you check your Healthmail account?

Daily

Weekly

Monthly

Rarely

5. How often do you receive a secure email via Healthmail?

Daily

Weekly

Monthly

Rarely

6. How many secure emails have you sent via Healthmail in the last week?

more than 10

between 5 and 9

less than 5

none 
* 7. Who are you communicating with using Healthmail? (tick all that apply)

HSE and Voluntary Hospitals

Private Hospitals and Clinics

$\square$ HSE Primary Care Unit (administration)

HSE Primary Care Teams (clinicians)

Mental Health services

GPS

$\square$ GP out of hours co-ops

Other

Other (please specify)

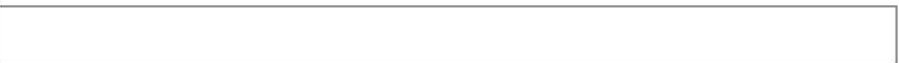

8. What do you mainly use Healthmail for? You can list up to three items.

1.

2.

3.

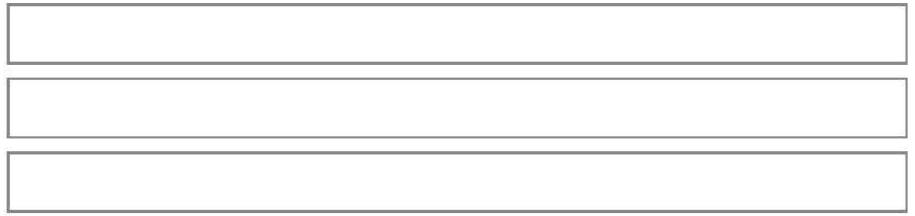

9. We would love to hear examples of how Healthmail has helped you or your patients. Could you please tell us your experiences? Please don't include any patient identifiable details. You can give up to three examples.

Example 1:

Example 2:

Example 3:

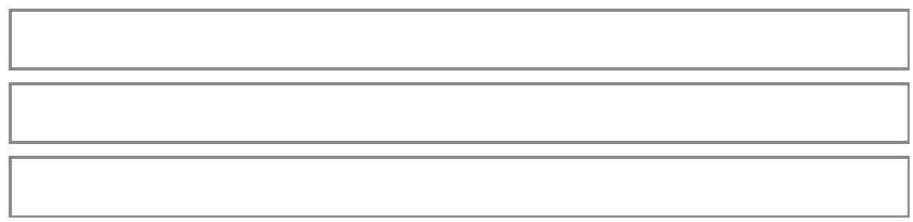

* 10. How useful is Healthmail for your practice/service?

very useful

somewhat useful

not useful 
11. Which of the following are important to make Healthmail more useful to you? Please tick all that apply.

Integration with GP practice software systems

Education and training for GPs in the use of Healthmail

Directory of HSE and Voluntary Hospital email addresses

Engagement with Healthmail by Hospitals

Engagement with Healthmail by Primary Care Clinicians

Promotion and marketing of Healthmail

Other, please specify

Other (please specify)

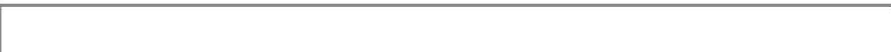

12. What should we do to improve the Healthmail service? You can enter up to three key actions.

1.

2

3.

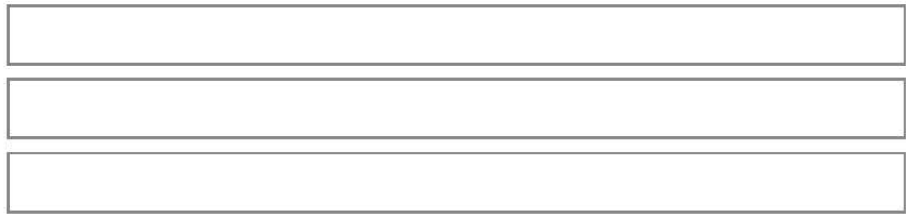

13. Would you like to see the Healthmail service expanded to other disciplines?

Yes

No

Don't Know

14. To which of the following would you like to see Healthmail expanded? Please tick all that apply.
Pharmacists
Dentists
Optometrists
$\square$ Nursing Homes
Other

Other (please specify) 
15. Would you be happy to communicate with your patients over a secure email solution?

Yes

No

Don't Know

16. In your opinion, does the Healthmail service improve patient care?

Yes

No

Don't Know

* 17 . Should the Healthmail service continue?

$\bigcirc$ Yes

No

Don't Know

18. What type of area do you practice in? (In this evaluation an urban area is defined as one with a population of 5,000 or more)

Urban

Mixed

Rural

* 19 . What is your gender?

Male

Female

$\star 20$. What is your age?

O $<35$

$35-54$

(55+ 
21. What Community Health Organisation $(\mathrm{CHO})$ area do you currently practice in?

CHO 1: Donegal, Sligo/Leitrim/West Cavan and Cavan/Monaghan

$\mathrm{CHO} 2$ : Galway, Roscommon and Mayo

$\mathrm{CHO}$ 3: Clare, Limerick, and North Tipperary/East Limerick

CHO 4: Kerry, North Cork, North Lee, South Lee, and West Cork

CHO 5: South Tipperary, Carlow/Kilkenny, Waterford and Wexford

CHO 6: Wicklow, Dun Laoghaire and Dublin South East

CHO 7: Kildare/West Wicklow, Dublin West, Dublin South City, and Dublin South West

CHO 8: Laois/Offaly, Longford/Westmeath, Louth and Meath

CHO 9: Dublin North, Dublin North Central and Dublin North West

22. If you have any comments or feedback on Healthmail, please enter them here:

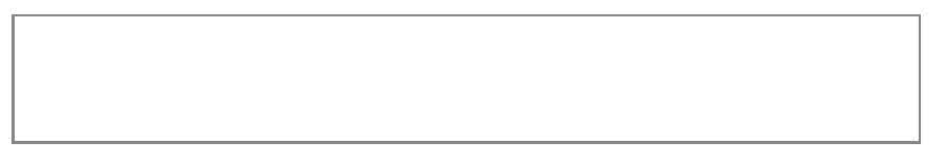

23. If you wish to enter the prize draw for free registration to the ICGP annual meeting, please enter your name and email address here. Please note that this will not be connected to your responses above, which will remain anonymous.
Name:
Email:

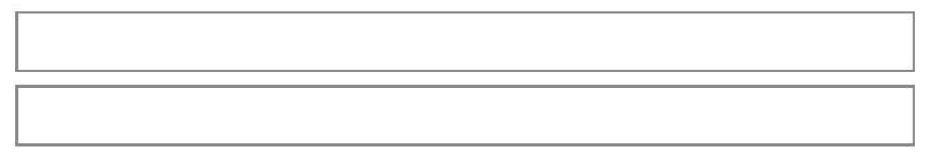




\section{REFERENCES}

[1] Healthmail. @Healthmail.ie, https://www.healthmail.ie/ (2014, accessed 13 December 2017).

[2] Hull K. Monthly Statistics and Graphs for Healthmail, secure clinical email, http://www.ehealthireland.ie/Access-to-Information/Health mail-/Healthmail-Monthly-Report-June-2018.pdf. （2018, accessed 03 August 2018).

[3] Kripalani S, LeFevre F, Phillips CO, et al. Deficits in communication and information transfer between hospital-based and primary care physicians: implications for patient safety and continuity of care. Jama 2007 Feb 28; 297(8):831-41.

[4] Anti-Phishing Working Group. Phishing Activity Trends Report 4th Quarter 2015, https://docs.apwg.org/reports/apw $\mathrm{g}$ trends report q4 2015.pdf (2015, accessed 13 December 2017).

[5] Martin G, Kinross J and Hankin C. Effective cybersecurity is fundamental to patient safety. BMJ 2017; 357. DOI: 10.1136/bmj.j2375.

[6] Ehrenfeld JM. WannaCry, Cybersecurity and Health Information Technology: A Time to Act. J Med Syst 2017; 41: 104 .

[7] Luna R, Rhine E, Myhra M, et al. Cyber threats to health information systems: A systematic review. Technol Health Care. 2016 Jan 1; 24(1):1-9.

[8] European Commission. EU Directive 95-46-EC - Data Protection Commissioner - Ireland; 2005.

[9] Data Protection Commissioner Ireland. General Data Protection Regulation. Ireland; 2017.

[10] Sawmynaden P, Atherton H, Sheikh A, Car J, Majeed A. Email for clinical communication between healthcare professionals. Cochrane Database of Systematic Reviews. 2012 Jan 1.

[11] Porteous T, Bond C, Robertson R, et al. Electronic transfer of prescription-related information: comparing views of patients, general practitioners, and pharmacists. Br J Gen Pract 2003 Mar 1; 53(488):204-9.

[12] Perera G, Holbrook A, Thabane L, et al. Views on health information sharing and privacy from primary care practices using electronic medical records. Int J Med Inform 2011 Feb 28; 80(2):94-101.

[13] Malka ST, Kessler CS, Abraham J, et al. Professional e-mail communication among health care providers: Proposing evidence-based guidelines. Acad Med 2015 Jan 1; 90(1):25-9.

[14] Atherton H, Car J, Meyer B. Email for clinical communication between patients/caregivers and healthcare professionals. Cochrane Db Syst Rev 2009 Jul 8(3).

[15] Starr P. Smart technology, stunted policy: developing health information networks. Health Affair 1997; 16: 91-105.

[16] Pappas Y, Atherton H, Sawmynaden P, et al. Email for clinical communication between healthcare professionals. Cochrane Db Syst Rev 2012 Jan 1; 9.

[17] eHealth Ireland. All Public Hospitals Now Receiving Electronic Referrals http://www.ehealthireland.ie/News-Media/News-Archive/2 016/All-public-hospitals-now-receiving-electronic-referral s.html (2017, accessed 13 December 2017).

[18] Karhula T, Kauppila T, Elonheimo O, Brommels M. Use of email in communication between the Finnish primary healthcare system and general practitioners. Journal of Innovation in Health Informatics. 2011; 19(1):25-32.

[19] Legris P, Ingham J, Collerette P. Why do people use information technology? A critical review of the technology acceptance model. Information \& management. 2003; 40(3):191-204.

[20] Car J, Black A, Anandan C, et al. The impact of eHealth on the quality and safety of healthcare. A Systemic Overview \& Synthesis of the Literature Report for the NHS Connecting for Health Evaluation Programme. 2008 Mar.

[21] Hobbs J, Wald J, Jagannath YS, et al. Opportunities to enhance patient and physician e-mail contact. Int $\mathrm{J}$ Med Inform 2003 Apr 30; 70(1):1-9.

[22] Castrén J, Niemi M, Virjo I. Use of email for patient communication in student health care: a cross-sectional study. BMC Med Inform Decis 2005 Dec 1; 5(1):2.

[23] Couchman GR, Forjuoh SN, Rascoe TG. E-mail communications in family practice. J Fam Practice 2001 May 1; 50(5):414-.

[24] Department of Health. Making the NHS more efficient and less bureaucratic,

https://www.gov.uk/government/publications/2010-to-201 5-government-policy-nhs-efficiency/2010-to-2015-govern ment-policy-nhs-efficiency (2015, accessed 13 December 2017).

[25] Royal College of General Practitioners. The 2022 GP. A Vision for general practice in the future NHS, http://www.rcgp.org.uk/campaign-home/ /media/files/poli cy/a-z-policy/the-2022-gp-a-vision-for-general-practice-inthe-future-nhs.ashx (2013, accessed 13 December 2017).

[26] O'Dowd T, O'Kelly M, O'Kelly F. Structure of General Practice in Ireland: 1982-2005. Department of Public Health and Primary Care, Trinity College Centre for Health Sciences [and] Irish College of General Practitioners; 2006.

[27] Van Geest JB, Johnson TP, Welch VL. Methodologies for improving response rates in surveys of physicians: a systematic review. Evaluation \& the Health Professions. 2007 Dec;30(4):303-21.

[28] Byrne M, Doherty S, McGee HM, Murphy AW. General practitioner views about discussing sexual issues with patients with coronary heart disease: a national survey in Ireland. BMC family practice. $2010 \mathrm{Dec} ; 11(1): 40$.

[29] O'Dea B, O'Connor P, Lydon S, et al. Prevalence of burnout among Irish general practitioners: a crosssectional study. Ir J Med Sci 2017; 186(2): 447-453. doi: 10.1007/s11845-016-1407-9 